\title{
Vandalismo ou iconoclastia? A fonte Ramos Pinto, no Rio de Janeiro
}

\section{Rafael Cardoso'}

Resumo: A fonte Ramos Pinto, instalada no Rio de Janeiro desde 1906, é caso ímpar para se pensar a relação entre vandalismo e iconoclastia. A peça é alvo de ataques cujo histórico se relaciona às políticas de remoção de favelas. O fato abre espaço para uma reflexão sobre exclusão social e a preservação do patrimônio histórico.

Palavras-chave: Vandalismo. Iconoclastia. Monumentos. Favelas.

\section{Vandalism or iconoclasm? The Ramos Pinto fountain in Rio de Janeiro}

\begin{abstract}
The Ramos Pinto fountain, installed in Rio de Janeiro since 1906, is a unique case for thinking about the relationship between vandalism and iconoclasm. The work has been repeatedly defaced in attacks linked to policies of razing favelas. This fact paves the way for thinking about how social exclusion relates to issues of heritage preservation.
\end{abstract}

Keywords: Vandalism. Iconoclasm. Monuments. Favelas. 


\section{Preâmbulo necessário}

Os últimos anos foram marcados por uma onda mundial de iconoclastia por motivo de protesto político. O marco inicial desse movimento foi a derrubada do monumento ao soldado confederado (conhecido como The Boys who wore Gray) na cidade de Durham, Carolina do Norte, em 14 de agosto de 2017, em reação direta à manifestação de extrema-direita Unite the Right ocorrida poucos dias antes em Charlottesville, Virginia. A partir daí, os Estados Unidos foram varridos por ataques a monumentos homenageando as forças sulistas durante a Guerra da Secessão americana, assim como outros vultos históricos implicados no sistema escravagista, e ainda Cristóvão Colombo, tido por lá como a personificação da chegada dos europeus às Américas e, portanto, como símbolo do colonialismo.

Essas ações se intensificaram após o assassinato de George Floyd e atravessaram o Atlântico, provocando a derrubada da estátua de Edward Colston - parlamentar britânico do século 17 e notório mercador de escravos - na cidade inglesa de Bristol no dia 7 de junho de 2020. O último ato obteve grande repercussão, sobretudo na imprensa de língua inglesa, como momento de internacionalização do movimento Black Lives Matter. Foi um episódio marcante, que deu urgência renovada à discussão existente desde 2015, quando se iniciou na África do Sul a campanha internacional Rhodes Must Fall - em prol da retirada de estátuas de Cecil Rhodes, magnata da mineração, fundador da antiga colônia britânica da Rodésia e imperialista mor. ${ }^{1}$

Para quem observa de fora da bolha anglófona, essa onda de protestos, dita global, pode ser vista também como produto da câmara de eco midiática entre Estados Unidos, Reino Unido e suas ex-colônias. Ao se espeIharem mutuamente, os países de língua inglesa tendem a negligenciar, ou mesmo excluir, o que acontece no resto do planeta. Não há nada de novo nos ataques a estátuas. A iconoclastia tem uma história longa, rica e complexa. Nem mesmo em seu aspecto descolonizador (ou decolonial, como preferem alguns), houve originalidade nesses atos. Quem acompanha o noticiário brasileiro lembra do ataque ao Monumento às Bandeiras, em

1 A. Kayum Ahmed, "\#RhodesMustFall: How a decolonial student movement in the Global South inspired epistemic disobedience at the University of Oxford", African Studies Review, 63/2 (2019), 281-303; Roseanne Chantiluke; Brian Kwoba \& Athinangamso Nkopo, orgs., Rhodes Must Fall: the Struggle to Decolonise the Racist Heart of Empire (Londres: Zed, 2018); e John Newsinger, "Why Rhodes Must Fall", Race \& Class, 58/2 (2016), 70-78. 
São Paulo, ocorrido no dia 2 de outubro de 2013, quando ativistas ligados aos direitos dos povos indígenas jogaram tinta vermelha na escultura de Victor Brecheret e picharam sobre ela a frase "Bandeirantes assassinos". Aquela ação, precursora da onda atual, é pouco mencionada na discussão global da descolonização de monumentos. Já o incêndio da estátua de Borba Gato, em Santo Amaro, no dia 24 de julho de 2021, conquistou manchetes internacionais, justamente por confirmar o alastramento da vaga 'iniciada' nos Estados Unidos.

Esse preâmbulo é para dizer que há uma distância imensa entre as ações transcorridas e os discursos construídos a partir delas. Cabe refletir antes de engrossar o coro que grita: vândalos, criminosos, bárbarie. Ao mesmo tempo, não se deve abraçar toda e qualquer depredação de monumento como ato libertário. Mesmo quando bem intencionada ou posta a serviço de uma causa nobre, a violência muitas vezes foge ao controle de quem a emprega. A iconoclastia pode ter consequências nefastas ou ser dirigida ao objeto errado. O recente incêndio do monumento ao Descobrimento do Brasil, no Rio de Janeiro, em 24 de agosto de 2021, é um exemplo de ação desacertada. Não atingiu seu alvo político, que seria de pressionar o STF no julgamento do marco temporal, e contribuiu para a deterioração de uma obra de valor artístico e histórico num contexto político em que o patrimônio já sofre de abandono crônico. O estrago nem sempre se resume aos danos materiais, mas se estende também à violência simbólica contra a memória cultural e a própria noção de coletividade.

A narrativa de uma nova iconoclastia serve a uma gama de interesses ideológicos. Forças políticas que nunca se importaram com o patrimônio histórico subitamente se arvoram em defensoras de monumentos, após décadas impondo arrocho e cortes de verba a órgãos de preservação. Com um discurso calculado para arrebanhar votos entre os partidários da ordem e dos privilégios, vozes conservadoras condenam ataques a monumentos, mas não hesitam em desestruturar os mecanismos estatais de proteção e fiscalização quando se trata de beneficiar a iniciativa privada e a especulação imobiliária. Não dão um pio, ademais, quando os atos de vandalismo são dirigidos a alvos que não lhes interessam - como a pichação de suásticas e símbolos de extrema-direita em locais ligados à memória judaica ou islâmica, africana ou indígena. Apesar da hipocrisia flagrante, essas forças seguem vencendo eleições. Todo cuidado é pouco, portanto, nessa discussão. 


\section{Um monumento sem monumentalidade}

O presente texto se dedica à discussão de um desses locais de memória negligenciados pelos paladinos do patrimônio, tanto os oportunistas quanto os verdadeiros. Trata-se do grupo escultórico conhecido no Rio de Janeiro sob o epíteto fonte Ramos Pinto ou, mais comumente, referida pelos habitantes da cidade como aquela escultura que fica na entrada do Túnel Novo, em frente ao Rio Sul, e vive sendo depredada. ${ }^{2}$ De fato, ao longo dos anos, a peça se tornou alvo preferencial para o vandalismo. Os ataques se avultaram nos anos 1990, deixando a superfície de mármore coberta de cima a baixo com tags e pichações em tinta spray. Posteriormente, a escultura foi depredada de modo mais agressivo, com a quebra de asas e braços das figuras, culminando em 2010 com a decapitação da figura que encima o grupo. Em 2013, uma restauração extensa visou reconstituir as estátuas, muito desfiguradas. ${ }^{3}$ Para quem não conhece a fonte Ramos Pinto e sua história, existe um resumo online com imagens atuais e históricas, assim como um vídeo documentando a restauração. ${ }^{4}$

O que provoca essa fúria contra a fonte Ramos Pinto? Seria uma revolta de ordem pragmática, por ela ser uma fonte sem água? Ou seria antes algo derivado da temática do monumento? Qual é sua temática, aliás? O que ela representa no plano simbólico? Apesar de poucos saberem os detalhes da obra - o título da escultura e seu autor são desconhecidos da vasta maioria - a fonte entrou para o repertório visual da cidade, suscitando numerosos artigos de imprensa ao longo das décadas, assim como fotografias e capas de revista [fig. 1-3], e virou referência geográfica de ambos os locais que ocupou desde sua inau-

2 Ver Ana Filipa Correia, A fonte Adriano Ramos Pinto: O vinho do Porto e a arte da belle époque no Rio de Janeiro (Porto: Adriano Ramos Pinto Vinhos S.A., 2000); e Vera Dias, "Inventário dos monumentos RJ"; http://www.inventariodosmonumentosrj.com.br/index.asp?iMENU=catalogo\&iiCO$D=313 \& i M O N U=F o n t e \% 20$ Ramos\%20Pinto, acessado em 14/09/2021.

3 Prefeitura da Cidade do Rio de Janeiro, "Conservação restaura monumento em Botafogo". http://www.rio.rj.gov.br/web/guest/exibeconteudo?id=4100975, acessado em 14/09/2021; e "Rio gasta R \$100 mil para reformar estátua que teve a cabeça arrancada", G1, 23/10/2012; http:// g1.globo.com/rio-de-janeiro/noticia/2012/10/rio-vai-gastar-r-100-mil-para-refazer-estatua-que-teve-cabeca-arrancada.html, acessado em 14/09/2021.

4 "A fonte Adriano Ramos Pinto: o vinho do Porto e a arte da belle époque no Rio de Janeiro"; https://vinhoculturaalimentar.wordpress.com/adriano-ramos-pinto/a-fonte-adriano-ramos-pinto-o-vinho-do-porto-e-a-arte-da-belle-epoque-no-rio-de-janeiro/, acessado em 14/09/2021. O vídeo está disponível também no Youtube, postado pela incansável defensora do patrimônio carioca Vera Dias; https://www.youtube.com/watch?v=8qq-0-OZFYl, acessado em 14/09/2021. 


\section{FON-FON}

Figura 3

Fon-Fon!, 16/02/1918

Capa: Hemeroteca

Digital Brasileira/

BN Digital/Fundação

Biblioteca Nacional

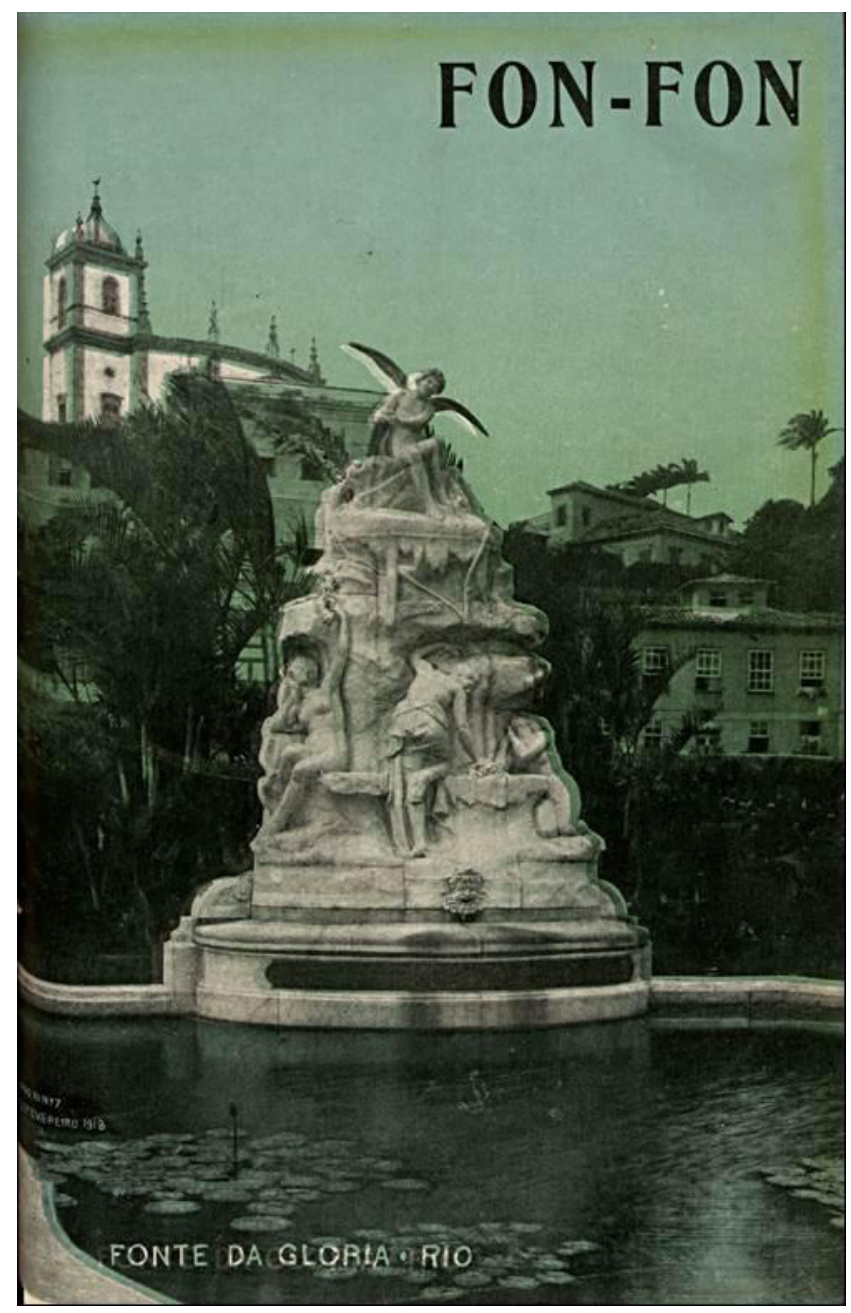

seguida, por pudor. ${ }^{6}$ A cobertura jornalística da época desmente ambas essas suposições. Mais de ano antes de ser inaugurada, o jornal Gazeta de Notícias estampou um desenho representando a peça em seu suplemento ilustrado de domingo. ${ }^{7} \mathrm{Na}$ manhã do grande dia, o Jornal do Brasil ostentou na primeira página uma gravura detalhada da peça, "de acordo com a última fotografia", elogiando sua perfeição e graciosidade. ${ }^{8}$ No dia seguinte,

6 Luciana Fróes, “Histórias para a quarentena: Quando o Rio 'vestiu' monumento dado por produtor de vinho do Porto", O Globo, 21/03/2020; https://blogs.oglobo.globo.com/luciana-froes/ post/historias-para-quarentena-quando-o-rio-vestiu-monumento-dado-por-produtor-de-vinho-do-porto.html, acessado em 14/09/2021.

7 “Uma dadiva portuguesa”, Gazeta de Notícias, 08/01/1905, suplemento ilustrado, 2.

8 "A fonte Ramos Pinto", Jornal do Brasil, 24/02/1906, 1. 
os relatos do Correio da Manhã e da Gazeta de Notícias destacaram apenas a beleza e o requinte da obra, assim como o brilhantismo da solenidade, que contou com a presença do presidente da República, do chefe da Casa Militar e do prefeito do Distrito Federal, além do ilustre doador portuense. ${ }^{9}$

Os diversos equívocos e notícias falsas em torno da história da peça fazem parte da discussão que se pretende levar a cabo aqui. São nas lacunas e nas aporias que se revela o sentido profundo da fonte intrusa. O que não se diz a seu respeito interessa bem mais para compreender a violência que lhe é dedicada do que os chavões repetidos sobre monumentos e vandalismo. É comum ouvir, mesmo de pessoas com conhecimento de assuntos de patrimônio cultural, que a depredação da fonte Ramos Pinto seria prova da ignorância do povo carioca, sua falta de apego a valores cívicos e seu despreparo para participar de um 'projeto civilizatório', assim chamado e vagamente definido. Vou argumentar aqui, ao contrário, que os ataques são indícios de uma guerra cultural que se trava, desde muito, na astúcia, na hipocrisia e no cinismo. De um lado estão os guardiães de um pacto social excludente; do outro, os excluídos que se recusam a ser silenciados. No meio, 37 toneladas de mármore e alguns sonhos despedaçados.

O uso do termo vandalismo, conforme observou Dario Gamboni, é sempre suspeito e carregado de juízos ocultos. ${ }^{10}$ A própria etimologia da palavra dá a pista. Ela foi cunhada após a Revolução Francesa, inspirada pela ideia de que os Vândalos, povo germânico que participou do terceiro saque de Roma no ano 455, seriam o protótipo para quem destrói obras de arte. Vandalismo é como chamamos a iconoclastia perpetrada pelos outros, culturalmente diferentes de nós, precisamente com o intuito de desqualificar tais atos e esvaziá-los de sentido maior. A reflexão aqui partirá de uma formulação alternativa, apelidando o suposto vandalismo de iconoclastia vulgar. Vulgar, no sentido de banal, corriqueira, comum, anônima, por não ter autoria assumida e não visar explicitamente uma finalidade religiosa ou política. Trata-se de um tipo de depredação que parece decorrer apenas do prazer de destruir. A palavra chave é parece. O fato de não

9 "Fonte artística. A inauguração", Correio da Manhã, 25/02/1906, 1; e "A inauguração da fonte artistica no jardim da Praça da Glória", Gazeta de Notícias, 25/02/1906, 8.

10 Dario Gamboni, The Destruction of Art: Iconoclasm and Vandalism since the French Revolution (Londres: Reaktion, 1997), esp. caps. 11 \& 15. 
declarar um teor ideológico manifesto não quer dizer necessariamente que a iconoclastia não possua um objetivo contestatório e mesmo civilizatório.

\section{Presente de português}

Por questão de método, compete recuar da discussão teórica sobre iconoclastia e recapitular a história da fonte Ramos Pinto, a começar pelo próprio nome. Adriano Ramos Pinto (1859-1927) foi fundador e sócio da empresa homônima, fabricante de vinhos do Porto estabelecida em Vila Nova de Gaia desde 1880. No final do século 19, época de grande reestruturação das empresas e dos mercados para o produto, as exportações para o Brasil representavam $30 \%$ do comércio mundial de vinho do Porto. ${ }^{11}$ Por volta de 1900 , Ramos Pinto optou pela estratégia de focar o mercado brasileiro. Os vinhos de sua marca aparecem anunciados reiteradamente na Revista da Semana, em 1901, sob o chamariz: "Porto-Brasil. Nova marca de vinho fino do Porto, autêntico, da muita acreditada casa exportadora Adriano Ramos Pinto \& C.". ${ }^{12}$ Até hoje, a firma se destaca por sua dedicação aos mercados sul-americanos, com ênfase no Brasil.

Ao longo de sua vida, Ramos Pinto reafirmou seu compromisso com o mercado brasileiro, assim como seu tino comercial. Esteve várias vezes no Brasil, e sua empresa adotou uma diversidade de ações promocionais que marcaram o cenário brasileiro. Além de derramar anúncios, cartazes e brindes na imprensa e no comércio, ela patrocinou o prêmio Adriano Ramos Pinto de remo, na década de 1910, e a taça Adriano Ramos Pinto de futebol, entre as décadas de 1920 e 1950. Em quase todo evento que agregasse a considerável comunidade portuguesa do Rio de Janeiro, o nome da firma estava presente. Só para citar um exemplo célebre, a festa aos aviadores portugueses Gago Coutinho e Sacadura Cabral, protagonistas do raid aéreo Lisboa-Rio em 1922, foi oferecida pela Ramos Pinto.

A primeira grande ação promocional empreendida por Adriano Ramos Pinto em solo brasileiro, a que colocou seu nome nos jornais e na boca do povo,

11 Conceição Andrade Martins, "Os ciclos do vinho do Porto: Ensaio de periodização", Análise Social, 24/100 (1988), 391-429.

12 Ver, entre muitos, Revista da Semana, 29/09/1901, 2. 
foi a doação de uma fonte para a cidade do Rio de Janeiro. ${ }^{13} \mathrm{O}$ plano surgiu de um entendimento entre o empresário e o prefeito Pereira Passos, em 1904, e foi anunciado nos seguintes termos pela imprensa:

\begin{abstract}
Vai possuir a cidade do Rio de Janeiro mais um belo monumento. É ele doado pelos conhecidos exportadores de vinho, residentes no Porto, Adriano Ramos Pinto \& C. Tendo adquirido a maior parte da sua fortuna em praças do Brasil, querem eles agora dar ao nosso país o testemunho da sua gratidão, oferecendo à capital da República uma soberba obra de arte, trabalho do grande escultor Teixeira Lopes. ${ }^{14}$
\end{abstract}

O local escolhido pelo prefeito para a instalação da fonte foi o jardim projetado para ocupar a área do antigo Mercado da Glória, demolido em função da abertura da Avenida Beira-Mar e reurbanização das adjacências, processo levado a cabo entre 1901 e $1904 .{ }^{15}$ O nome do escultor português António Teixeira Lopes, natural de Vila Nova de Gaia, foi indicação do próprio Ramos Pinto, mas não resultou, já que o estatuário recusou a encomenda, alegando excesso de outros compromissos.

Determinado a concretizar a doação da fonte com toda a agilidade possível, Ramos Pinto viajou para Paris, onde contratou os serviços de Eugène Thivier, escultor pouco conhecido, hoje lembrado principalmente pela obra simbolista Le cauchemar (1894), pertencente ao Musée des Augustins, em Toulouse. O andamento dos trabalhos foi noticiado com avidez pela imprensa carioca, ao longo de 1904 e $1905 .{ }^{16}$ O Correio da Manhã veiculou a informação, fornecida pelo próprio artista em carta a Ramos Pinto, da qualidade da pedra usada para a escultura:

13 “Adriano Ramos Pinto", Gazeta de Noticias, 04/02/1906, 2.

14 "Offerta de um monumento", Correio da Manhã, 27/04/1904, 1. Ver ainda "Notas e notícias", Gazeta de Notícias, 29/03/1904, 1.

15 Correio da Manhã, 05/05/1901, 1. A área corresponde hoje, aproximadamente, ao logradouro denominado Praça Nossa Senhora da Glória. Para melhor visualização da geografia, muito alterada por sucessivos projetos de urbanização, ver o vídeo "O grandioso Mercado da Glória e sua demolição - Rio de Janeiro antigo"; https://www.youtube.com/watch?v=19tK7IPgHFc, acessado em 16/09/2021.

16 Ver, entre outros, "Notas e notícias", Gazeta de Notícias, 12/08/1904, 1; "Notas e notícias", Gazeta de Notícias, 07/10/1904, 1; "Notas e notícias", Gazeta de Notícias, 23/12/1904, 1; "Notas e notícias", Gazeta de Notícias, 14/01/1905, 1; Correio da Manhã, 28/02/1905, 1; "Prefeitura", Correio da Manhã, 09/05/1905, 4; "Fonte artistica", Gazeta de Noticias, 04/11/1905, 2; "Vida portugueza. A fonte para o jardim da Glória", Correio da Manhã, 15/12/1905, 4; "Fonte monumental", Gazeta de Notícias, 31/12/1905, 3. 
Os técnicos e operários encarregados de fazer extrair os mármores da Itália tiveram a fortuna de encontrar um bloco talvez único, de que conseguiram tirar as três figuras principais da Fonte. Essas figuras são de um tom absolutamente uniforme e sem mancha alguma. ${ }^{17}$

Em entrevista ao correspondente da Gazeta de Notícias, o empresário portuense também frisou a sorte desse achado:

Os práticos que partiram para a Itália em procura do mármore, começavam já a se desesperar de descobrir o que se desejava, quando, depois de longas e fatigantes buscas, encontraram por um desses acasos providenciais, um bloco único, monumental, sem uma única mancha, do qual se extraíram as três figuras de mulher. ${ }^{18}$

É notável o interesse despertado pela brancura e perfeição do mármore, sem mancha alguma, o que contrasta de modo gritante com o destino eventual da obra como suporte para pichações de todas as cores.

A obra entregue por Thivier em 1905 teve sua maquete exposta no Salão de 1904 da Société des Artistes Français, com o título Fontaine de Jouvence. ${ }^{19}$ Esse nome - que quer dizer fonte da juventude, em português - não consta da extensa cobertura jornalística dedicada ao assunto. Ao invés, a peça aparece na imprensa sob designações diversas: fonte Ramos Pinto, fonte da Glória, fonte do Jardim da Glória, fonte das ninfas. Isso revela o quão pouco os atributos propriamente escultóricos - tema e tratamento - influíram na recepção brasileira da obra. A fonte foi percebida, em primeiro lugar, não como obra de arte, mas como doação de Ramos Pinto. Era um monumento à sua generosidade e prova da estima existente entre Brasil e Portugal. Em sua crônica semanal para a Gazeta de Notícias, o poeta Olavo Bilac deu voz ao sentimento que atravessa a cobertura da época:

E essa fonte não representa apenas um melhoramento urbano: representa um exemplo e uma lição, que convém registrar e louvar. Dois industriais estrangeiros, que ganham bastante dinheiro no Brasil, quiseram mostrar a sua gratidão ao povo que os

17 "Vida portugueza. Fonte d'arte", Correio da Manhã, 30/10/1905, 3.

18 "A fonte monumental para o Rio de Janeiro", Gazeta de Notícias, 14/12/1905, 3.

19 Société des Artistes Français [organizado por Ludovic Bachet], Catalogue illustré du Salon de 1904 (Paris: Librarie d'Art, 1904), seção de escultura, número 3314. 
favorece. Consideraram que a capital da República está num período de transformação, e quiseram associar-se a esse trabalho de saneamento e aformoseamento. Ah! se todos os que aqui realizam bons negócios quisessem fazer o mesmo! ${ }^{20}$

Em segundo lugar, a fonte Ramos Pinto foi entendida como contribuição ao processo de reforma urbana da cidade, encapsulado no mote o Rio civiliza-se (popularizado pelo jornalista Alberto Figueiredo Pimentel na seção "Binóculo" do jornal Gazeta de Notícias). As reportagens frisam com frequência o fato da peça ter sido encomendada em Paris, reconhecida como capital artística do mundo, e carregam nos elogios ao obscuro escultor francês, frequentemente tratado de renomado e insigne artista. Na mesma crônica citada no parágrafo anterior, Bilac resume também essa dimensão civilizatória, ao comentar a boa aceitação do novo Jardim da Glória:

[...] o povo adotou-o imediatamente: é o ponto predileto das crianças do bairro, e ainda não houve ali uma flor arrancada, um galho quebrado, um canteiro de relva maltratado. Agora, a fonte artística, de claro mármore risonho, vem dar um novo encanto àquele logradouro delicioso, em que o bom gosto da Prefeitura transformou o sítio do antigo Mercado, de ignóbil e odiada memória. ${ }^{21}$

Dois aspectos desse trecho são dignos de nota. Primeiramente, o absoluto desprezo com que Bilac desdenha o recém-demolido Mercado da Glória, imensa construção e um dos marcos da paisagem carioca no século 19. O segundo é a ênfase dada pelo autor ao fato de não haver vandalismo direcionado ao novo jardim - nem um galho quebrado ou uma flor arrancada. Esse floreio retórico dá a entender, nas entrelinhas, que a inexistência de maus tratos seria algo surpreendente, como se fosse uma prova de que o referido bom gosto da Prefeitura estava a despertar uma nova civilidade da parte da população.

Ramos Pinto tirou bom proveito de sua doação. Ficou conhecido por esse ato de desprendimento, referido como o homem da fonte, e celebrado por imprensa e dignatários no Brasil. Presumivelmente, essa boa reputação lhe foi útil nos diversos litígios em que esteve envolvido, principalmente por questões de propriedade industrial e disputas de marca. A empresa fez uso

20 O.B., "Chronica”, Gazeta de Notícias, 25/02/1906, 5.

21 Ibid. 
direto da peça como propaganda, chegando inclusive a produzir um vinho de nome Porto Fonte, cujo rótulo era ilustrado com uma representação da peça de Thivier. Esse aspecto publicitário era suficientemente acentuado para que, em 1921, um colunista irado desmerecesse a obra como "aquela fontezinha-reclame que o sr. Adriano Ramos Pinto mandou de Portugal, com

Figura 4

Correio da Manhã,

$11 / 03 / 1956$

$2^{\circ}$ caderno, 4

Hemeroteca Digital Brasileira/BN

Digital/Fundação

Biblioteca Nacional umas amostras do seu vinho do Porto, e que o Prefeito Passos fincou ali no Largo da Glória". 22 Mesmo após a morte do fundador, a empresa continuou a lançar mão de sua fonte para fins publicitários. Um anúncio de jornal de 1956 [fig. 4], ilustrado com desenho do grupo escultórico em sua nova localização em frente ao Túnel Novo, comemorava o "Cinquentenário da Fonte Ramos Pinto. Esta fonte é parte de nossa tradição!". ${ }^{23}$

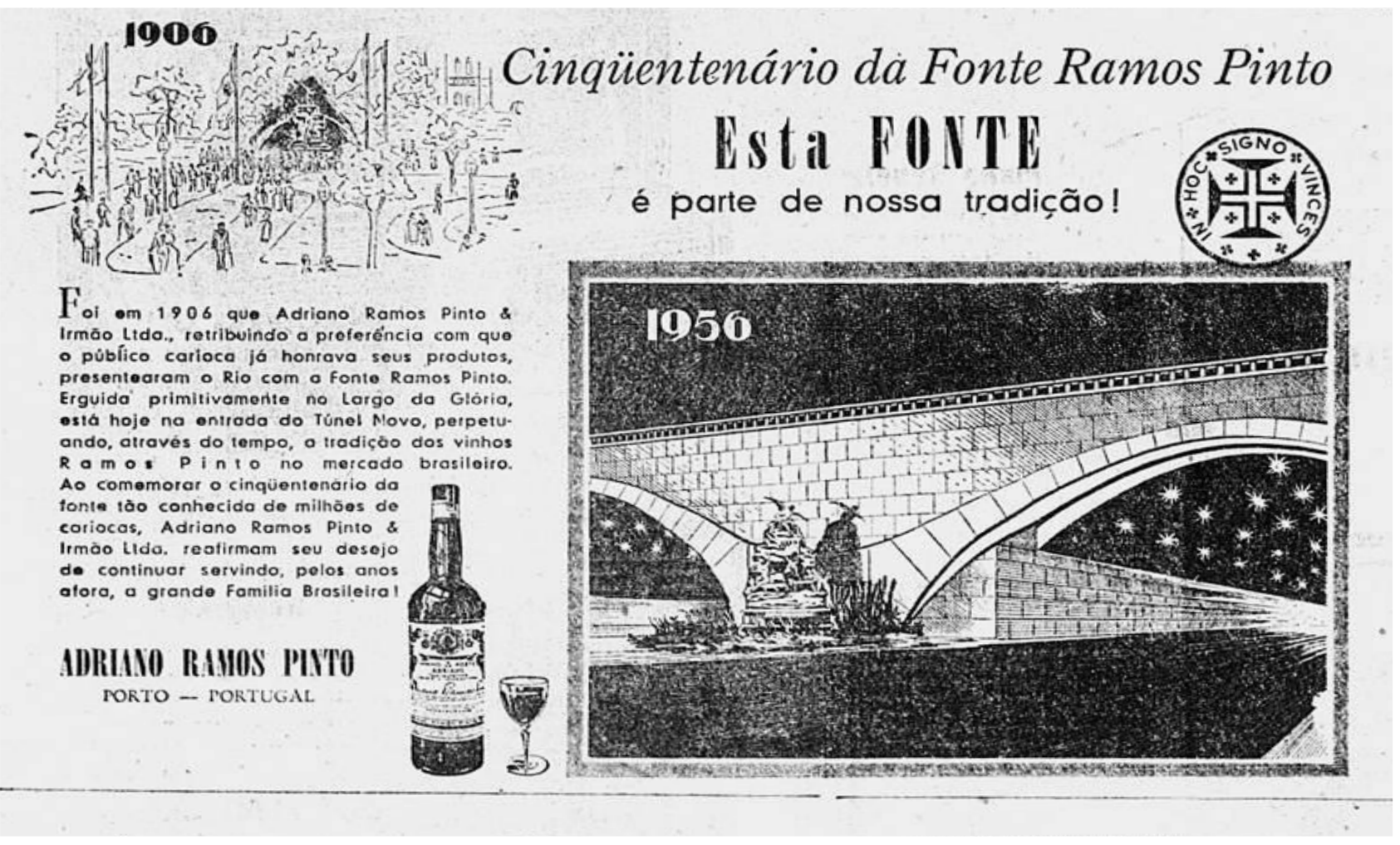

22 Ildefonso Falcão, "O Theatro 'Cervantes'”, Careta, 26/11/1921, s.p.

23 Correio da Manhã, 11/03/1956, $2^{\circ}$ caderno, 4. 
Após a inauguração da segunda galeria (Túnel Engenheiro Marques Porto) do Túnel Novo, sob o governo do prefeito Mendes de Morais, a Prefeitura efetuou em 1950 a transferência da fonte Ramos Pinto para o local que ocupa atualmente. ${ }^{24}$ Ali começou uma nova etapa, bem diferente, da existência da obra. Para começar, ela foi despojada da grande bacia d'água que a circundava no Jardim da Glória, conforme se observa em fotografias da época. Sem ligação hidráulica, a fonte Ramos Pinto deixou de funcionar como fonte, embora nem por isso tenha perdido o nome. A mudança de cenário também alterou de modo visceral a relação da obra com o espaço público. Antes situada num jardim, local de permanência e lazer, ela passou a ocupar a faixa intermediária entre duas pistas automotivas de alta velocidade, até hoje um dos eixos viários mais importantes de conexão entre Centro e Zona Sul. Na prática, isso significou que poucas pessoas iriam parar para contemplar a peça ou interagir com ela, já que o logradouro - designado oficialmente de Praça Juliano Moreira, mas conhecido como uma terra de ninguém - é de difícil acesso para pedestres. Assim, o grupo escultórico se tornou objeto para ser visto de relance por quem passasse por ali de carro ou ônibus.

Em 1958, ocorreu a primeira depredação da fonte Ramos Pinto. A peça amanheceu sem a cabeça, asas e braços da figura ao topo e com danos a outras figuras. Em reportagem denunciando o abandono da cidade, o Correio da Manhã apontou o dedo para o crescimento da favela no Morro da Babilônia, cujos barracos se derramavam pela lateral da pista automotiva junto à Igreja de Santa Teresinha. Segundo o jornal, os danos às estátuas coincidiram com o surgimento de doze novos barracos:

No dia seguinte ao da instalação dos barracos apareceu danificada a obra de arte que, numa homenagem ao Brasil, Adriano Ramos Pinto doou ao Rio de Janeiro. Instalaram a obra à entrada do túnel, junto ao paredão do morro. Desse paredão atiraram grandes pedras que atingiram a parte superior da obra arrebentando a cabeça e braços da primeira figura. As pedras pesam cinco quilos e foram jogadas de propósito, com o objetivo de causar danos. Caso de Polícia que infelizmente não toma conhecimento dessas coisas. ${ }^{25}$ 
A reportagem era ilustrada com uma foto mostrando os estragos [fig. 5]. Não se trata de uma reação espontânea de indignação da parte do jornal, e muito menos é coincidência a menção a moradores da favela. Ao longo dos anos 1950 e 1960, o Correio da Manhã, de propriedade da família Bittencourt, se engajou em campanha sistemática de combate às favelas e em prol da sua remoção. ${ }^{26}$

Figura 2

Correio da Manhã, 31/08/1958

$4^{\circ}$ caderno, 1 ; Hemeroteca Digital Brasileira/BN Digital/Fundação Biblioteca Nacional

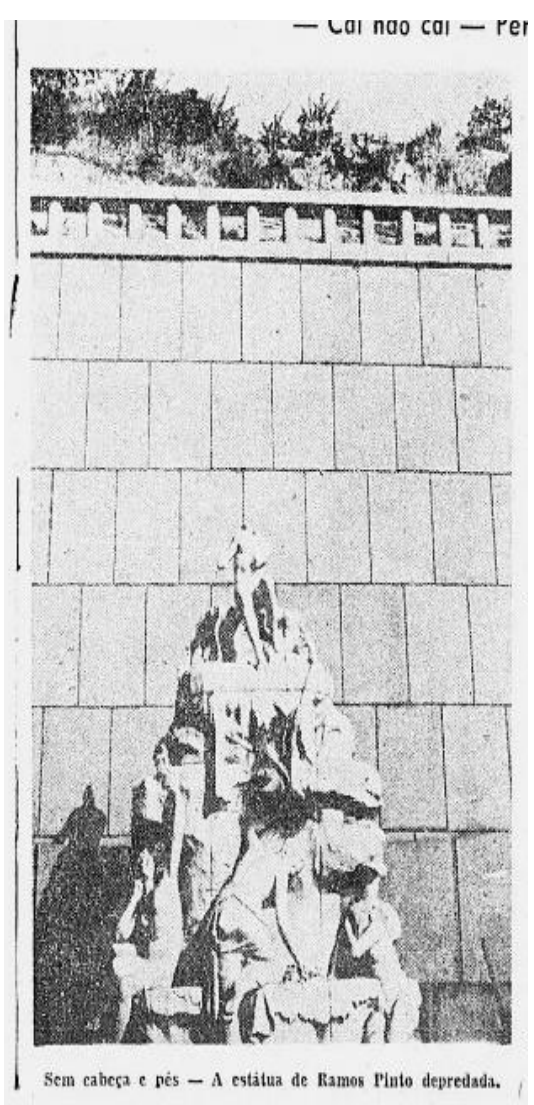

Em 1966, a coluna intitulada "Gerico" - área editorial do Correio da Manhã que fazia uma espécie de plantão do cotidiano da cidade - denunciava "os efeitos do mais baixo vandalismo cometido contra um dos mais belos

31/08/1958, $4^{\circ}$ caderno, 1.

26 Letícia Sabina Wermeier Krilow, "Favela representada: Disputas em torno de nomeações e significações nas páginas dos jornais cariocas (1951-1954)", Crítica Histórica, 10/20 (2019), 79-110; https://www.seer.ufal.br/index.php/criticahistorica/article/download/9044/pdf, acessado em $17 / 09 / 2021$ 
monumentos da Zona Sul." Nova foto mostrava a figura ao topo do grupo escultórico sem cabeça, asas e braços, mais uma vez. Ignorando aparentemente o ocorrido em 1958, a reportagem informou:

Ocorre que vândalos, residentes na favela local, há um ano iniciaram a destruição do monumento. Inicialmente, munidos de pedras, de sobre a entrada do túnel bombardearam-no, partindo as asas da artística figura, aliás a principal, ponto culminante da fonte. Agora, utilizando-se de pedras cujos pesos variavam de 3 a 4 quilos - pois ainda lá estão - destruíram os braços e a cabeça da bela escultura. Isso tudo, agora que o monumento se apresenta irrecuperável, deve-se à omissão das autoridades que fecharam os olhos ante o barbarismo dos moleques da favela, rapazes de mais de 15 anos de idade. ${ }^{27}$

No ano seguinte, o Gerico voltou à tona, requerendo das autoridades que removessem a fonte para o outro lado (Copacabana) do túnel, onde estaria a abrigo dos lançadores de pedras. A essa altura, parece que a reportagem havia se inteirado do episódio anterior, de 1958, pois escreveu:

Queremos fazer sentir ao Departamento de Parques e Jardins que tal restauração e a conservação do monumento no mesmo local será praticamente inútil, pois a ação dos vândalos se fará sentir novamente, uma vez que esta é a terceira vez que o mesmo sofre atentados. ${ }^{28}$

Não há como saber se o Gerico estava ou não certo com relação à autoria dos ataques. É bem possível que sim, mas também é plausível que não. Seja isso como for, sua previsão de que as ações se fariam sentir novamente só veio a ser confirmada décadas depois, em 2010, quando da nova decapitação do grupo escultórico. Nessa ocasião mais recente, contudo, ao que indicam os tags pichados - que incluíram a assinatura "Lido", área próxima no bairro de Copacabana - as forças antagônicas à fonte Ramos Pinto haviam se alastrado por um território maior do que a favela do Morro da Babilônia.

\section{Iconoclastia vulgar e uma guerra peculiar}

As acusações do Correio da Manhã contra os "moleques da favela" podem parecer uma simples constatação de fatos. Questão de falar a verdade, doa a

27 “Gerico", Correio da Manhã, 01/10/1966, $2^{\circ}$ caderno, 4.

28 "Gerico. Removam o monumento", Correio da Manhã, 21/10/1967, $2^{\circ}$ caderno, 4. 
quem doer, e, portanto, apenas o exercício do bom jornalismo. Porém, vindo de onde vieram e pelas datas em que foram publicadas, as notas do Gerico podem ser entendidas também como uma provocação. Faz-se necessária uma pequena explicação para quem não conhece a geografia histórica do Rio de Janeiro. O Morro da Babilônia, rocha que separa os bairros de Botafogo, Urca e Leme, abriga duas favelas: Babilônia e Chapéu-Mangueira, que possuem históricos e perfis demográficos distintos. ${ }^{29} \mathrm{~A}$ menos de um quilômetro ao norte, seguindo o eixo viário que passa pela Túnel Novo, existiu uma terceira favela, no vizinho Morro do Pasmado, removida entre 1963 e 1964 por ação da Secretaria de Serviços Sociais do Estado da Guanabara, então dirigida por Sandra Cavalcanti. Atendendo à forte pressão da campanha conduzida pelo Correio da Manhã, o governo Carlos Lacerda removeu os moradores, arrasou as edificações e, numa apoteose de intento espetaculoso, mandou o corpo de bombeiros incendiar os escombros da favela na noite de 24 de janeiro de $1964 .^{30}$

O governador Lacerda tinha como plataforma eleitoral as questões de saneamento e embelezamento da cidade, principalmente da Zona Sul, em preparação para as comemorações do quarto centenário do Rio de Janeiro em 1965. Daí o empenho agressivo do seu governo em políticas higienistas de remoção de favelas e combate a moradores de rua. ${ }^{31}$ Nessa frente, ele teve um forte aliado no jornal da família Bittencourt, que martelou críticas ao alastramento das favelas, alardeou o sucesso das ações lideradas por Sandra Cavalcanti e promoveu a hipótese de que fossem estendidas a outras favelas. ${ }^{32}$ A favela da Catacumba, incendiada duas vezes, em 1967 e 1968,

29 Clara Polycarpo, "Favelas Chapéu-Mangueira e Babilônia", https://wikifavelas.com.br/index. php/Favelas_Chap\%C3\%A9u-Mangueira_e_Babil\%C3\%B4nia, acessado em 16/09/2021.

30 Júlio Bizarria, "O Morro do Pasmado e suas cidades virtuais: Do Correio da Manhã à nova militância das favelas", Pontourbe: Revista do Núcleo de Antropologia Urbana da USP, 15 (2014); https://journals.openedition.org/pontourbe/2493, acessado em 15/09/2021.

31 Ver Mariana Dias Antonio, "A 'Operação mata-mendigos' (Rio de Janeiro, 1962-1963) à margem de alguns livros", Simbiótica. Revista Eletrônica, 7/2 (2020), 163-180; Thársyla Glessa Lacerda da Cunha, "Remoção de favelas durante o governo Carlos Lacerda (1960-1965): Propriedade para os pobres ou favorecimento aos ricos?", Revista Convergência Crítica, 12 (2017), 130-147; Mario Brum \& Rafael Soares Gonçalves, "O Rio do IV Centenário aos 450 anos: Novas funções da cidade e o passado como obstáculo", Cadernos de Desenvolvimento Fluminense, 7 (2015), 37-56; e Mario Sergio Brum, "Favelas e remocionismo ontem e hoje: Da ditadura de 1964 aos grandes eventos", O Social em Questão, 29 (2013), 179-207.

32 Ver, entre outros, "Sandra no Pasmado explica o despejo", Correio da Manhã, 11/12/1963, $1^{\circ}$ caderno, 2; "Morro do Pasmado já não tem favela", Correio da Manhã, 18/01/1964, $1^{\circ}$ caderno, 3; “UDN espera sinal de CL para a sucessão na GB", Correio da Manhã, 26/01/1964, $1^{\circ}$ caderno, 6; 
e efetivamente removida em 1969, e a favela da Praia do Pinto, incendiada e removida em 1969, demonstram a continuidade dessa política de erradicação, conjugada a incêndios suspeitos, sob o governo Negrão de Lima. ${ }^{33}$

Dado esse clima, é lícito presumir que os moradores de outras favelas da Zona Sul, como a do Morro da Babilônia, se perguntassem se não seriam os próximos. Antes mesmo da remoção da favela do Pasmado, o Gerico fez uma comparação direta entre ela e os barracos recentes nas adjacências do Túnel Novo, sugerindo que o novo assentamento em breve seguiria o caminho de favelização do Morro do Pasmado. ${ }^{34} \mathrm{~A}$ sensação de insegurança para os moradores de favelas da Zona Sul vinha se acentuando desde o início da década de 1950, quando a remoção de assentamentos na orla marítima suscitou aplausos efusivos do Correio da Manhã. ${ }^{35}$

O primeiro ataque à fonte Ramos Pinto, em 1958, é contemporâneo à erradicação da favela do Morro de Santo Antônio, no Centro, cujo arrasamento assinalou que mesmo os assentamentos mais antigos não estavam a salvo das políticas de remoção. O segundo ataque, em 1966, ocorreu sob o fantasma da remoção recente da favela do Pasmado e o terceiro, em 1967, poucos meses após o primeiro incêndio da Catacumba. Ante essa cronologia - e, vale frisar, caso tenham sido mesmo perpetrados por moradores da favela da Babilônia - seria no mínimo ingênuo caracterizar esses atos iconoclastas como mero vandalismo, desprovido de intuito político. Posto o contexto de criminalização das favelas até hoje vigente, toda ação de depredação do patrimônio valorizado pela chamada 'boa sociedade' é passível antes de ser vista como grito de protesto. Do gênero: já que não tenho nada, vou destruir o que é seu, até porque nunca será meu mesmo.

\footnotetext{
"Vila é longe mas favela era pior", Correio da Manhã, 30/01/1964, $1^{\circ}$ caderno, 5; "Secretaria critica ministro Jurema", Correio da Manhã, 15/02/1964, 1 caderno, 2; "CL lança Beltrão para governar GB", Correio da Manhã, 14/03/1964, $1^{\circ}$ caderno, 2.

33 Dicionário de Favelas Marielle Franco, "Favela da Catacumba"; https://wikifavelas.com.br/ index.php?title=Favela_da_Catacumba; e "Praia do Pinto"; https://wikifavelas.com.br/index.php?title=Praia_do_Pinto, ambos acessados em 16/09/2021.

34 "Gerico. E uma nova favela vai surgindo", Correio da Manhã, 22/02/1963, $1^{\circ}$ caderno, 4.

35 "Removidas algumas favelas da orla marítima", Correio da Manhã, 15/06/1952, 4 caderno, $1,3$.
} 
Aqueles que não se sentem incluídos no concerto cultural simbolizado por determinado tipo de obra de arte não têm nenhum motivo para venerar uma produção que lhes é alienígena. Com sua temática classicizante de ninfas e cupidos e sua linguagem vagamente simbolista, importadas diretamente da Paris da virada do século 20, a Fontaine de Jouvence de Thivier possui tanta relevância para o repertório do adolescente carioca médio quanto uma pia batismal católica transplantada para o deserto do Uzbequistão. Ela é, e sempre foi, um corpo estranho, fincado na paisagem carioca como uma bandeira de explorador. O mármore, branquíssimo, sem uma única mancha, é quase um chamariz para quem se sente maculado pela nódoa do racismo estrutural. Um convite ao risco e ao rabisco... como uma página em branco, ou um muro recém caiado. Não se pode ignorar, portanto, a dimensão de guerra cultural e/ou luta de classes existente nas ações de depredação contra a fonte Ramos Pinto.

Mesmo partindo da suposição contrária, de que a coluna Gerico tenha se enganado e que as depredações não fossem obra de moradores da favela, o gesto de rebeldia que é atacar um monumento em pleno espaço público encerra o potencial de arrebanhar adeptos de origens sociais diversas. A pichação e a depredação são conhecidas por seu papel sociológico na demarcação de territórios e disputas entre grupos de adolescentes. Isso é fortalecido num ambiente político autoritário, como foi o período pós-1964 no Brasil, em que a contestação da autoridade ganha contornos de ação heroica. Além do mais, em termos psíquicos, há algo de libertador e mesmo erótico no ato de ferir a superfície lisa da estátua. Esse aspecto tampouco deve ser negligenciado, sob pena de subestimar a dimensão profunda da iconoclastia. ${ }^{36}$ Apesar dessas considerações, nem os transtornos da juventude transviada, nem o conflito favela $x$ asfalto, são os únicos caminhos para entender a violência contra a fonte Ramos Pinto.

A primeira depredação do grupo escultórico ocorreu em 1958, antes do acirramento da campanha pela erradicação das favelas da Zona Sul, que atingiu seu ápice na década de 1960. O fator decisivo para despertar as ações

36 Ver Kenneth Gross, The Dream of the Moving Statue (Ithaca: Cornell University Press, 1992), 9-10. Ver ainda Hal Foster, "The art of fetishism: notes on Dutch still life", In: Emily Apter \& William Pietz, orgs., Fetishism as Cultural Discourse (Ithaca: Cornell University Press, 1993), 251-265; e David Freedberg, The Power of Images: Studies in the History and Theory of Response (Chicago: University of Chicago Press, 1989), 10-11. 
iconoclastas parece ter sido mesmo a mudança de localização, da Glória para Botafogo. Para refletir sobre o significado profundo desse deslocamento, vale recorrer ao conceito da produção social do espaço consagrado pelo filósofo Henri Lefebvre. ${ }^{37}$ Pensando na distinção estabelecida por Lefebvre entre espaços percebido, concebido e vivido, pode-se argumentar que a transferência do monumento para o Túnel Novo engendrou um esgarçamento da unidade entre essas três dimensões.

No Jardim da Glória, a fonte Ramos Pinto era percebida como cumprindo a função social para qual foi concebida - a saber, o embelezamento da cidade com o propósito de elevar o padrão civilizatório da população. Pelo menos durante o período em que se conseguiu manter os melhoramentos decorrentes da reurbanização de 1904 a 1906, a vivência do local tendia a confirmar essa percepção, engendrando uma unidade entre as três dimensões espaciais. A coincidência entre o percebido (beleza e harmonia), o concebido (ordem e civilidade) e o vivido (lazer e segurança) permaneceu mais ou menos em equilíbrio por algumas décadas. Com o deslocamento da peça para a entrada do Túnel Novo - eliminando sua função como fonte e removendo-a de um espaço ajardinado e aprazível - ficou evidente o quanto a vivência da peça destoava de sua concepção. A esse rompimento entre concebido e vivido, seguiu-se uma mudança gradativa do entendimento da obra, que deixou de ser vista como integrada ao seu entorno e passou a ser percebida como um monumento fora do lugar.

Para além dessas dimensões espaciais, pesou também contra a peça uma dialética temporal entre embelezamento e arrasamento, muito característica da evolução do Rio de Janeiro. A reforma urbana promovida por Pereira Passos, para a qual a fonte Ramos Pinto é uma pequena contribuição, foi precedida pelo gigantesco bota-abaixo que fez desaparecer a cidade do século 19. Incluído nos escombros dessa ruína estava o Mercado da Glória, cuja ausência assombra o surgimento do jardim que o substituiu. O Jardim da Glória, por ironia do destino, também sumiu, consumido por novas ondas de reurbanização. A mania de demolir o antigo em nome da construção do novo não é restrita ao início do século 20 . Na única grande capital do

37 Ver Christian Schmid [traduzido por Maria Inez Medeiros Marques \& Marcelo Barreto], "A teoria da produção do espaço de Henri Lefebvre: Em direção a uma dialética tridimensional", GEOUSP - Espaço e Tempo, 32 (2012), 89-109. 
mundo a arrasar seu núcleo fundador por livre e espontânea vontade, não se deve subestimar a sanha pela destruição. O Rio é uma cidade que cultua a nostalgia por seu passado desaparecido - vide a proliferação de sites e livros dedicados ao tema Rio Antigo - mas tem uma ficha corrida paradoxal de derrubar ou deixar ruir o patrimônio existente. ${ }^{38}$

O urbanismo do Rio pode ser caracterizado como voraz. A história fundiária da cidade está repleta de exemplos de lotes edificados, arrasados e reconstruídos múltiplas vezes no prazo histórico curtíssimo de algumas décadas. A especulação imobiliária tem forte papel nisso, mas não explica casos como o Palácio Monroe ou o antigo edifício da Academia de Belas-Artes, destruídos para dar lugar ao vazio. Nesse contexto, o que hoje é visto como embelezamento, tende a virar objeto de arrasamento amanhã ou depois de amanhã.

Por que motivo seria diferente com a fonte Ramos Pinto? Seria sua proposta civilizatória em mármore italiano e gosto francês mais adaptada às intempéries da cidade nos trópicos do que as tantas rochas de gnaisse desmontadas com o intuito de abrir caminho para o progresso? Morro do Senado, Morro do Castelo, Morro de Santo Antônio, entre outros removidos para aterrar litorais, lagoas e rios, fazendo desaparecer as praias, ilhas e águas viventes da cidade, empurrando para os subterrâneos a diversidade que a natureza fez ali aflorar. É pedir demais à pobre peça escultórica, encomendada às pressas por um empresário propenso a abrir mercados, que ela faça frente a um processo histórico de tamanha dimensão.

Às vezes, o vandalismo vem de cima. Conforme alertaram alguns dos grandes historiadores do tema - Louis Réau, Martin Warnke, Colin Ward - a destruição do patrimônio histórico pelas ações de urbanismo e políticas de planejamento costuma ser maior do que aquela praticada pelas mãos dos pequenos vândalos. É o que Dario Gamboni apelidou de vandalismo embelezador. ${ }^{39} \mathrm{O}$ Rio de Janeiro não foge a essa regra. Comparada às violências perpetradas pelos reformadores que derrubaram a Praça Onze e a Igreja de São Pedro dos Clérigos para rasgar a Avenida Presidente Vargas;

38 Ver Arquivo Geral da Cidade do Rio de Janeiro, Memória da destruição: Rio, uma história que se perdeu, 1889-1965 (Rio de Janeiro: Prefeitura da Cidade do Rio de Janeiro, 2002).

39 Gamboni, The Destruction of Art, cap. 11. 
o Convento da Ajuda para fazer a Cinelândia; o Morro do Castelo para abrir um vazio que até hoje não se preencheu, entre muitos e muitos outros exemplos, a depredação da fonte Ramos Pinto é café pequeno. A única força que concorre com o poder público em termos de aniquilamento da memória da cidade é a especulação imobiliária. Esta, a fim de lucrar no curto prazo, não hesita em arrasar mesmo o que se acabou de reconstruir. Talvez seja o caso de considerar o que estou chamando aqui de iconoclastia vulgar em conjunção com o conceito de vandalismo embelezador. Um não é o contrário do outro, mas são movimentos complementares.

\section{Para fechar, uma alegoria}

O território do Rio de Janeiro é um estranhíssimo arquipélago, onde diversas ilhas de civilidade convivem em meio a um mar de barbárie (não há outra palavra para uma cidade onde as vidas de tantas crianças são sacrificadas às balas chamadas de perdidas). As ilhas são regidas por um pacto social que exclui, historicamente, os que foram condenados a viver no mar. Sujeitados à dura vida embarcada, os marítimos dedicam-se à pirataria. Invadem as ilhas e pilham o que podem, de modo oportunista. Os ilhéus os olham com desprezo. Julgam-nos marginais e selvagens, incapazes do bom convívio social. Por precaução, vivem a reforçar seus sistemas de defesa e patrulhamento das águas. De tempos em tempos, alguém sugere que a incivilidade dos marítimos deriva da vida a que foram constrangidos pela lei antiga que os lançou ao mar. Propõe que a solução dos problemas seja de lhes abrigar também em terra, como concidadãos. Regida pelo medo e a ira, a maioria dos ilhéus costuma rejeitar tais delírios. Mandam o sujeito ir morar num bote, já que gosta tanto dos marítimos. Em seguida, encomendam um novo sistema de defesa, avançadíssimo, importado do continente para onde os ilhéus mandam seus filhos estudar. Lá, há museus e monumentos lindíssimos.

\section{Referências}

A fonte Adriano Ramos Pinto: o vinho do Porto e a arte da belle époque no Rio de Janeiro"; https://vinhoculturaalimentar.wordpress.com/adriano-ramos-pinto/a-fonte-adriano-ramos-pinto-o-vinho-do-porto-e-a-arte-da-belle-epoque-no-rio-de-janeiro/, acessado em 14/09/2021.

A fonte monumental para o Rio de Janeiro", Gazeta de Notícias, 14/12/1905. 
A fonte Ramos Pinto", Jornal do Brasil, 24/02/1906.

Adriano Ramos Pinto", Gazeta de Notícias, 04/02/1906.

AHMED. A. Kayum Ahmed. "\#RhodesMustFall: How a decolonial student movement in the Global South inspired epistemic disobedience at the University of Oxford", African Studies Review, 63/2 (2019), 281-303.

ANTONIO, Mariana Dias. "A 'Operação mata-mendigos' (Rio de Janeiro, 1962-1963) à margem de alguns livros", Simbiótica. Revista Eletrônica, 7/2 (2020), 163-180.

Arquivo Geral da Cidade do Rio de Janeiro, Memória da destruição: Rio, uma história que se perdeu, 1889-1965 (Rio de Janeiro: Prefeitura da Cidade do Rio de Janeiro, 2002).

BIZARRIA, Júlio. "O Morro do Pasmado e suas cidades virtuais: Do Correio da Manhã à nova militância das favelas", Pontourbe: Revista do Núcleo de Antropologia Urbana da USP, 15 (2014); https://journals.openedition.org/ pontourbe/2493, acessado em 15/09/2021.

BRUM, Mario Sergio. "Favelas e remocionismo ontem e hoje: Da ditadura de 1964 aos grandes eventos", O Social em Questão, 29 (2013), 179-207.

CHANTILUKE, Roseanne; KWOBA, Brian \& NKOPO, Athinangamso (orgs.). Rhodes Must Fall: the Struggle to Decolonise the Racist Heart of Empire. Londres: Zed, 2018.

CL lança Beltrão para governar GB", Correio da Manhã, 14/03/1964, $1^{\circ}$ caderno.

CORREA, Magalhães. "Terra carioca. Recordações das fontes e chafarizes", 08/06/1930, 3; Luiz Edmundo, "O Rio de Janeiro do meu tempo", Correio da Manhã, 31/03/1935, suplemento.

CORREIA, Ana Filipa. A fonte Adriano Ramos Pinto: $O$ vinho do Porto e a arte da belle époque no Rio de Janeiro. Porto: Adriano Ramos Pinto Vinhos S.A., 2000.

Correio da Manhã, 05/05/1901. 
Correio da Manhã, 11/03/1956, $2^{\circ}$ caderno.

Correio da Manhã, 28/02/1905.

DA CUNHA, Thársyla Glessa Lacerda. "Remoção de favelas durante o governo Carlos Lacerda (1960-1965): Propriedade para os pobres ou favorecimento aos ricos?", Revista Convergência Crítica, 12 (2017), 130-147.

De olho nos grandes problemas, a municipalidade esqueceu as ruas", Correio da Manhã, 31/08/1958, 4º caderno.

DIAS, Vera. "Inventário dos monumentos RJ"; http://www.inventariodosmonumentosrj.com.br/index.asp?iMENU=catalogo\&iiCOD=313\&iMONU=Fonte\%20Ramos\%20Pinto, acessado em 14/09/2021.

Dicionário de Favelas Marielle Franco, "Favela da Catacumba"; https:// wikifavelas.com.br/index.php?title=Favela_da_Catacumba; e "Praia do Pinto"; https://wikifavelas.com.br/index.php?title=Praia_do_Pinto, ambos acessados em 16/09/2021.

FALCÃO, Ildefonso. “O Theatro 'Cervantes'”, Careta, 26/11/1921.

Fon-Fon!, 15/02/1913, capa; Fon-Fon!, 16/02/1918.

Fonte artística. A inauguração", Correio da Manhã, 25/02/1906, 1; e "A inauguração da fonte artística no jardim da Praça da Glória", Gazeta de Notícias, 25/02/1906.

Fonte artística", Gazeta de Notícias, 04/11/1905.

Fonte monumental", Gazeta de Notícias, 31/12/1905.

Fonte Ramos Pinto", Revista da Semana, 20/07/1940.

FOSTER, Hal. "The art of fetishism: notes on Dutch still life", In: Emily Apter \& William Pietz, orgs., Fetishism as Cultural Discourse. Ithaca: Cornell University Press, 1993.

FREEDBERG, David. The Power of Images: Studies in the History and Theory of Response.Chicago: University of Chicago Press, 1989. 
FRÓES, Luciana. “Histórias para a quarentena: Quando o Rio 'vestiu' monumento dado por produtor de vinho do Porto”, O Globo, 21/03/2020; https:// blogs.oglobo.globo.com/luciana-froes/post/historias-para-quarentena-quando-o-rio-vestiu-monumento-dado-por-produtor-de-vinho-do-porto. html, acessado em 14/09/2021.

GAMBONI, Dario. The Destruction of Art: Iconoclasm and Vandalism since the French Revolution. Londres: Reaktion, 1997.

Gerico. E uma nova favela vai surgindo", Correio da Manhã, 22/02/1963, $1^{\circ}$ caderno.

Gerico. Removam o monumento", Correio da Manhã, 21/10/1967, $2^{\circ}$ caderno.

Gerico", Correio da Manhã, 01/10/1966, $2^{\circ}$ caderno.

GONÇALVES, Rafael Soares \& BRUM, Mario. "O Rio do IV Centenário aos 450 anos: Novas funções da cidade e o passado como obstáculo", Cadernos de Desenvolvimento Fluminense, 7 (2015), 37-56;

GROSS, Kenneth. The Dream of the Moving Statue. Ithaca: Cornell University Press, 1992.

KRILOW, Letícia Sabina Wermeier Krilow. "Favela representada: Disputas em torno de nomeações e significações nas páginas dos jornais cariocas (1951-1954)", Crítica Histórica, 10/20 (2019), 79-110; https://www.seer. ufal.br/index.php/criticahistorica/article/download/9044/pdf, acessado em $17 / 09 / 2021$.

MARTINS, Conceição Andrade Martins. "Os ciclos do vinho do Porto: Ensaio de periodização", Análise Social, 24/100 (1988), 391-429.

Morro do Pasmado já não tem favela", Correio da Manhã, 18/01/1964, $1^{\circ}$ caderno.

N.C., "Vida cultural. Inauguração de uma fonte artística", Correio da Manhã, 24/02/1959, $1^{\circ}$ caderno, 17.

NEWSINGER, John. “Why Rhodes Must Fall”, Race \& Class, 58/2 (2016), 70-78. 
Notas e notícias", Gazeta de Notícias, 07/10/1904.

Notas e notícias", Gazeta de Notícias, 12/08/1904.

Notas e notícias", Gazeta de Notícias, 14/01/1905.

Notas e notícias", Gazeta de Notícias, 23/12/1904.

Notas e notícias", Gazeta de Notícias, 29/03/1904.

O.B. [Olavo Bilac], “Chronica”, Gazeta de Notícias, 25/02/1906.

Offerta de um monumento", Correio da Manhã, 27/04/1904.

POLYCARPO, Clara Polycarpo. "Favelas Chapéu-Mangueira e Babilônia", https://wikifavelas.com.br/index.php/Favelas_Chap\%C3\%A9u-Mangueira_e_Babil\%C3\%B4nia, acessado em 16/09/2021.

Prefeitura da Cidade do Rio de Janeiro, "Conservação restaura monumento em Botafogo". http://www.rio.rj.gov.br/web/guest/exibeconteudo?id=4100975, acessado em 14/09/2021.

Prefeitura", Correio da Manhã, 09/05/1905.

Removidas algumas favelas da orla marítima", Correio da Manhã, 15/06/1952, $4^{\circ}$ caderno.

Revista da Semana, 06/08/1938.

Revista da Semana, 29/09/1901.

Rio gasta $\mathrm{R} \$ 100$ mil para reformar estátua que teve a cabeça arrancada", G1, 23/10/2012; http://g1.globo.com/rio-de-janeiro/noticia/2012/10/ rio-vai-gastar-r-100-mil-para-refazer-estatua-que-teve-cabeca-arrancada. html, acessado em 14/09/2021.

Sandra no Pasmado explica o despejo", Correio da Manhã, 11/12/1963, $1^{\circ}$ caderno.

SCHIMD, Christian [traduzido por Maria Inez Medeiros Marques \& Marcelo 
Barreto]. "A teoria da produção do espaço de Henri Lefebvre: Em direção a uma dialética tridimensional”, GEOUSP - Espaço e Tempo, 32 (2012), 89-109.

Secretaria critica ministro Jurema", Correio da Manhã, 15/02/1964, $1^{\circ}$ caderno.

Société des Artistes Français [organizado por Ludovic Bachet], Catalogue illustré du Salon de 1904 (Paris: Librarie d'Art, 1904), seção de escultura, número 3314.

Transformações da cidade", Correio da Manhã, 10/06/1952, $1^{\circ}$ caderno.

UDN espera sinal de CL para a sucessão na GB", Correio da Manhã, 26/01/1964, $1^{\circ}$ caderno.

Uma dadiva portuguesa", Gazeta de Notícias, 08/01/1905, suplemento ilustrado.

Vida portugueza. A fonte para o jardim da Glória", Correio da Manhã, $15 / 12 / 1905$.

Vida portugueza. Fonte d'arte", Correio da Manhã, 30/10/1905.

Vila é longe mas favela era pior", Correio da Manhã, 30/01/1964, 1 caderno. 